\title{
Pathophysiology of tethered cord syndrome and similar complex disorders
}

\author{
Shokei Yamada, M.D., Ph.D., ${ }^{1}$ Daniel J. Won, M.D., ${ }^{2}$ Gholam PezeshKPour, ${ }^{3}$ M.D., \\ Brian S. Yamada, M.D., ${ }^{4}$ ShoKo M. Yamada, M.D., M.Sc., ${ }^{5}$ JaVEd SiddiQi, M.D., \\ F.R.C.S.C., D.PHIL., ${ }^{6}$ AleXANDER Zouros, M.D., F.R.C.S.C., ${ }^{1}$ \\ Austin R. T. Colohan, M.D. ${ }^{1}$ \\ ${ }^{1}$ Department of Neurosurgery, Loma Linda University School of Medicine, Loma Linda; \\ ${ }^{2}$ Division of Pediatric Neurosurgery and ${ }^{3}$ Department of Pathology, Kaiser Permanente Medical \\ Center, Fontana; ${ }^{6}$ Department of Neurosurgery, Arrowhead Regional Medical Center, Colton, \\ California; ${ }^{4}$ Capital Region Urological Surgeons, PLLC, Albany, New York; and \\ ${ }^{5}$ Department of Neurosurgery, Nippon Medical School, Tokyo, Japan
}

\begin{abstract}
$\checkmark$ Tethered cord syndrome (TCS) is a stretch-induced functional disorder of the spinal cord due to the fact that its caudal portion is anchored by an inelastic structure. The functional lesion of TCS is generally situated in the lumbosacral cord, and many authors have shown that the syndrome is reversible via surgery to untether the cord. To clarify the expressions relevant to TCS, such as "cord tethering" and "tethered cord," the authors have formulated three categories. These categories include cases that show the anatomical appearance of spinal cord stretching. Among them, Category 1 is isolated to represent the "true TCS."

The authors focus their discussion of the pathophysiology of TCS on Category 1 to explain the impaired oxidative metabolism and electrophysiological derangements within the tethered spinal cord, which is the primary intrinsic cause of the dysfunction. Furthermore, they extend the discussion to the extrinsic (outside the spinal cord) factors and other complex conditions that mimic TCS. (DOI: 10.3171/FOC-07/08/E6)
\end{abstract}

KEY WORDS • tethered cord syndrome - tethered spinal cord • inelastic filum

I N 1940, Lichtenstein ${ }^{17}$ proposed that lesions induced by tethering of the spinal cord occur in patients with a myelomeningocele. He attributed lumbosacral lesions manifested by paraplegia or paraparesis and Chiari malformation to the downward spinal cord traction caused by this anomaly. Although this hypothesis was not accepted by Barry et al., ${ }^{1}$ Barson, ${ }^{2}$ and Gardner et al., ${ }^{5}$ two major questions remained to be answered. First, if tethering-induced symptoms exist, what part of the nervous system is affected? Second, what is the pathophysiological basis for any reversible lesion?

In 1976 Hoffman et al. ${ }^{10}$ adopted the term "tethered spinal cord" in a report on 32 patients who presented with motor and sensory deficits in the lower limbs and incontinence, which subsided after sectioning the thickened terminal filum. These clinical findings clearly localized reversible lesions in the lumbosacral cord, which was under excessive tension. In 1981 Yamada et al. ${ }^{51}$ demonstrated

\footnotetext{
Abbreviations used in this paper: ATP $=$ adenosine 5'-triphosphate; $\mathrm{MR}=$ magnetic resonance; $\mathrm{SSEP}=$ somatosensory evoked potential; TCS $=$ tethered cord syndrome.
}

that oxidative metabolism was impaired in the lumbosacral cord in patients who had clinical presentations similar to those in Hoffman and colleagues' patients. ${ }^{10}$ These study data also confirmed parallel metabolic and neurological improvement after untethering surgery.

Such data offered answers to the two questions previously posed by many neurosurgeons (F. Anderson, personal communication). At the American Association of Neurological Surgeons meeting in 1987, however, McLone and Naidich debated the topic "Is the TCS fact or fiction?" One conclusion drawn was that TCS is a clinical entity based on scientific fact. Since then, the term "TCS" has increasingly appeared in the neurosurgical literature..$^{18,23}$

To further clarify definitions and the TCS syndrome itself, we propose the following categorization. ${ }^{46}$ Category 1 includes patients whose neurological symptomatology is correlated with the traction effect on the spinal cord above the tethering site and below the counteracting site, that is, usually at the lowest pair of dentate ligaments attached to the T12-L1 cord segments. ${ }^{51}$ Patients with an inelastic filum, a sacral myelomeningocele continuous with the cau- 
dal spinal cord, and a caudal or small transitional lipomyelomeningocele belong to this category. The signs and symptoms of these patients are reversible. Apparently tethered spinal cord ${ }^{10}$ with an elongated cord and thick filum is a typical example of TCS associated with an inelastic filum.

Category 2 includes patients with anomalies to the dorsal aspect of a higher cord level (between L-1 and S-1). Many myelomeningoceles and some of the dorsal or large transitional lipomyelomeningoceles belong to this category. The symptomatology may be partly the manifestation of TCS and partly the result of local effects or the latter alone. Often, fibrous tissue associated with cord compression or ischemia and impaired cerebrospinal fluid circulation is responsible for local dysfunction. Accordingly, signs and symptoms in patients in Category 2 are only partially reversible or unchanged after attempted untethering surgery ${ }^{41}$ and often require repeated surgeries. ${ }^{26}$

Category 3 patients do not show signs and symptoms of TCS, although the spinal cord appears to be tethered. Among this category, one subgroup includes paraplegic and totally incontinent patients in whom the spinal cord is anchored by an inelastic structure, mostly at a high lumbar or thoracic level. They apparently have no functional neurons in the lumbosacral cord. In some patients with lipomyelomeningocele, fat tissue extends into the spinal cord, replacing neuronal tissue. Another subgroup includes asymptomatic patients with an elongated cord and a thick terminal filum. The term "TCS" is not applied to these patients because the syndrome is meant to be a special neurological complex.

\section{Biochemical and Biophysical Mechanisms of TCS}

The central nervous system relies absolutely on oxidative metabolism to produce ATP, which is the energydonating molecule necessary for neuronal function and cell survival. ${ }^{24}$ Whenever oxidative metabolism is impaired in the central nervous system, the pathophysiological consequences are quickly evident and often irreversible depending on the extent and duration of the impairment. As is relevant to a discussion of TCS, mild-to-moderate spinal cord stretching has been shown to have effects similar to mild hypoxemia, whereas severe stretching produces effects expected from prolonged ischemia. This link among spinal cord stretching, impaired oxidative metabolism, and derangements in electrical activities in the interneurons of the spinal cord was described in a prior article ${ }^{48}$ published in Neurosurgical Focus as well as in other papers. The correlation among electrophysiological cord activity, glucose metabolism, blood flow, and histological studies in experimental TCS is described in the following sections to emphasize the importance of impaired oxidative metabolism in this pathological entity.

\section{Redox Studies in an Experimental Model of Tethered Spinal Cord}

Insights into the link between spinal cord stretching and pathophysiologies of oxidative metabolism and neuronal function were derived predominantly from studies in cat models during and after spinal cord traction. ${ }^{51}$ Authors of these studies took advantage of the fact that changes in oxidative metabolism can be indicated by recording shifts in the reduction/oxidation (redox) ratios of the components of the mitochondrial electron transport chain by noninvasive, reflection spectrophotometry. Such shifts in redox ratios are indicative of oxidative metabolism because oxygen consumption and ATP production are tightly coupled to mitochondrial electron transport. ${ }^{3,24}$

Acutely Tractioned Spinal Cord. In cat models, shifts toward a reduction in cytochrome $\mathrm{a}, \mathrm{a}_{3}$ occurred as the spinal cord was stretched with weights. Three patterns of metabolic effects were noted as the spinal cord was stretched: ${ }^{51}$ 1) With low-grade traction (2 g), there was only a small shift toward a reduction in cytochrome $\mathrm{a}, \mathrm{a}_{3}$ (this was called the Type 1 pattern). When the traction weight was removed, cytochrome $\mathrm{a}, \mathrm{a}_{3}$ quickly underwent an oxidative shift back to its pretraction redox ratio (normal level). 2) With medium-grade traction (3-4 g), cytochrome $\mathrm{a}, \mathrm{a}_{3}$ became moderately reduced (Type 2 pattern). Removal of the traction was also followed by rapid recovery of this cytochrome to its pretraction redox state. 3) High-grade traction $(5 \mathrm{~g})$ produced marked shifts toward a reduction in cytochrome $\mathrm{a}, \mathrm{a}_{3}$. When this level of traction was removed, recovery of the pretraction redox state of cytochrome $\mathrm{a}, \mathrm{a}_{3}$ was prolonged and incomplete (Type 3 pattern).

The changes in mitochondrial redox ratios and interneuron potential changes that occurred in animal models of spinal cord traction were similar to those observed during hypoxemia and ischemia. ${ }^{48}$ Notably, the effects of mild-tomoderate cord traction and mild-to-moderate hypoxemia or ischemia were reversible, whereas severe traction produced irreversible changes. During severe traction, cytochrome $\mathrm{a}, \mathrm{a}_{3}$ becomes increasingly reduced, whereas the decrease in blood flow remains the same as the level under moderate-grade traction. ${ }^{14,36,40}$ This dissociation of redox changes and blood flow decreases may be explained by electron microscopic studies that have shown neuronal membrane stretch. ${ }^{40}$ This structural change suggests that exchanges in ions through the membranes are disturbed and that mitochondria could also be deformed, possibly leading to energy deficiency.

Chronically Tractioned Cord in Experimental TCS. In this section we discuss the long-term effects of isometric cord stretching in experimental models and compare these effects with those of acute stretching of spinal cords by isotonic traction. We want to understand the spinal cord adjustments that can occur under steady stretching (as compared with transient stretching) without additional stresses after vertebral growth has temporarily or permanently stopped.

The acute studies previously described were conducted in cat spinal cords, first under isotonic traction and then after traction was converted to isometric stretching. This process was accomplished by first placing a 2-0 silk ligature on the terminal filum and connecting to different weights. ${ }^{51}$ The spinal cord was stretched with a 3- or 5-g weight. A 4-0 silk suture was tied around the ligature knot and stitched to the dura mater to secure the ligature while traction was maintained. The behavior of the animals was observed for 1, 3, 6, and 9 months, and at each of these time points spectrophotometric recordings of redox shifts in cytochrome $\mathrm{a}, \mathrm{a}_{3}$ were performed on the exposed spinal 
cord in vivo. ${ }^{40}$ Then the animals were killed, and spinal cord specimens were histologically studied using light and electron microscopy.

The hind limbs became weakened when the spinal cords underwent 3- and 5-g (equivalent) traction, and the weakness was worse with the greater traction weight. Cats whose spinal cords were stretched with $3 \mathrm{~g}$ of traction could run and jump naturally within 2 months after traction was begun; animals with spinal cords stretched with $5 \mathrm{~g}$ of weight required from 4 to 6 months to regain the same physical ability. Incontinence was noted for several days in animals that had undergone chronic 3-g traction and for 2 to 3 weeks in those subjected to chronic 5-g traction.

Mitochondrial redox activity, as indicated by responses to brief periods of hypoxia or nerve root stimulation, was not different from that in controls at the time of death. No histological changes were produced by chronic traction, as noted on light and electron microscopy in the lumbar, sacral, and coccygeal cord..$^{22}$

Restoration of mitochondrial redox activity paralleled recovery of physical activity in these cats. Neurological deficits (motor, sensory, and bladder dysfunction) in humans have appeared to be linked with mitochondrial dysfunctions without histologically demonstrable damage..$^{40}$ Some suggest that the plasticity of neurons and glia plays a role in promoting restoration of function during chronic cord tethering and could be the mechanism of symptomatic fluctuation or arrest in children with TCS. The temporary arrest of symptom progression in young children may be due to the spinal cord growth in response to the excessive tension. ${ }^{1}$

\section{Glucose Metabolism in States of Cord Traction}

Another insight into the mechanisms of mitochondrial changes due to cord stretching was recently derived from the monitoring of glucose metabolism via quantitative autoradiography in animal models. The distribution volume and plasma concentration of deoxyglucose can be determined using this technique. This procedure is quantitative because mathematical models allow calculation of local deoxyglucose uptake, which is related to local glucose utilization. ${ }^{30}$ Data obtained during such procedures in the in vivo brain, for example, have confirmed the tight coupling among the functional state of a brain or spinal cord region, its local metabolic rate, and its blood flow. ${ }^{39}$

In studies of cord tethering performed at Loma Linda University, the spinal cords of anesthetized cats were subjected to either no traction (controls) or 3- or 5-g traction. The cats received an intravenous injection of 2-D-deoxyglucose $(12 \mathrm{nCi} / \mathrm{kg})$. The animals were killed after 15 minutes, and the descending aorta was cannulated for perfusion with a glutaraldehyde/formaldehyde mixture. After fixation, the lumbosacral segments were removed and stored at $-70^{\circ} \mathrm{C}$. The frozen cords were later sectioned into 10- to $20 \mu \mathrm{m}$-thick sections from the L-7 and S-2 cord segments. Autoradiography was performed using standard techniques. The films were developed and analyzed for relative glucose consumption by using a densitometer.

Compared with controls (no traction), 3-g traction had only a mild effect on glucose consumption, but 5-g traction significantly decreased glucose consumption at the L-
7 and S-2 levels. These results indicate that glucose metabolism is altered in parallel to the redox alterations in cytochrome $\mathrm{a}_{,} \mathrm{a}_{3} .{ }^{39}$

We propose that these changes are linked to the electrical suppression due to cord traction. Whether the putatively linked changes in glucose consumption and electron transport are attributable to decreased ATP use from electrical depression or to decreased oxygen delivery, which secondarily causes electrical depression, remains to be determined. With mild-to-medium traction, decreased glucose consumption, indicated by mildly impaired 2-deoxyglucose metabolism, was consistent with mild cytochrome reduction, which correlated with the reversibility of neurological dysfunction.

\section{Redox Studies in Patients With TCS}

Reflection spectrophotometric monitoring of redox shifts in mitochondrial cytochrome $\mathrm{a}_{,} \mathrm{a}_{3}$ was accomplished in the lumbosacral spinal cords of 57 patients. To determine the basic redox state of the cytochrome $\mathrm{a}, \mathrm{a}_{3}$, the spinal cords were subjected to short periods of hypoxic stress or neuronal stimulating stress.

Patients were divided into three groups according to TCS signs and symptoms. Group 1 had preoperative presentation with mild symptoms of TCS. These patients showed mildly reduced cytochrome before untethering and a normal redox state after untethering. They regained normal neurological function within several weeks after untethering surgery. Patients in Group 2 showed moderate TCS symptomatology prior to surgery. They had a moderate reduction in cytochrome before untethering and shifted to the normal redox state after untethering. Neurological signs improved to normal within several months. Patients in Group 3 had moderate-to-severe TCS symptoms before surgery. In these patients, cytochrome a, $\mathrm{a}_{3}$ was very reduced before untethering, and although surgery effected some shifts toward oxidation of this cytochrome, levels remained more reduced than those in patients in either Group 1 or 2 after the untethering surgery. Postoperative neurological improvement was slow (6 months or longer), and in most of these patients, neurological improvement was not complete 2 years after the untethering procedures.

These data support the conclusion that shifts toward mitochondrial oxidation occur after untethering the cord in patients with TCS. These shifts are predictive of neurological improvement after untethering and indicate that the patients really had TCS. The effects of cord tethering and untethering corresponded to changes in blood flow, as revealed by Schneider et al. ${ }^{25}$

\section{Essential Factors for TCS}

Hoffman and colleagues ${ }^{10}$ originally described two anatomical features in patients with a tethered spinal cord: an elongated cord and a thickened terminal filum. These features are often considered to be absolute criteria in the diagnosis of this disorder. As the number of patients with a diagnosis of tethering-induced symptomatology increased, however, neurosurgeons began asking whether an elongated cord or thickened filum or both were essential for the development of TCS. 
This questioning of the anatomical criteria for TCS was brought to the forefront by the surgical experiences of Warder and Oakes, ${ }^{38}$ who reported no cord elongation in $18 \%$ of their patients, and Yamada and colleagues, ${ }^{42,49}$ who found that $28 \%$ of adult and late teens patients with typical signs and symptoms of TCS showed neither cord elongation nor a thickened terminal filum. ${ }^{42,49}$ To pursue this subject, we collected relevant clinical and experimental data as follows.

\section{Embryological and Pathophysiological Analysis of Elongated Spinal Cords and Thickened Terminal Filum}

It was initially speculated that the elongated, thickened spinal cords in patients with TCS indicated spinal cord overgrowth, as suggested by Barry et al. ${ }^{1}$ in patients with myelomeningocele. This theory is supported by data from the recent landmark studies conducted by Pfister et al.,21 who showed stretch-induced axonal growth. This conclusion was elicited from observations of posterior ganglion cells removed from rat embryos. After continuous extreme stretching of integrated axons (by traction) for 24 hours, these axons (not the growing axons) lengthened 10fold from baseline, and their diameters increased by $35 \%$. Conceivably, if the newly developed caudal spina cord and terminal filum are surrounded by mesodermal tissue and if fibrous tissue starts to grow into the terminal filum in human embryos (in the 9th week), cord tension could increase as the spine grows, which could cause the lower spinal cord and filum to grow unusually longer and thicker (Fig. 1). In normally developing embryos, however, the coccygeal medullary vestige is isolated from the terminal filum (during the 9th-11th weeks), presumably preventing mesodermal tissue from growing into the filum.

Pfister and associates ${ }^{21}$ also found the boundary of nerve growth and disconnection (Fig. 1). To the right of this boundary, axonal growth was accelerated as long as tension was increased, but axonal disruption occurred in the gray zone (on the left). Slightly right of the boundary, neuronal dysfunction was expected, as in tethered spinal cord. One can postulate that an elongated cord is likely to have occurred from its stretching during at least one embryonic period and that the patient with an elongated and thickened filum has a higher potential for tethered spinal cord (with symptoms typical for TCS) than those with nonelongated cords.

\section{Diameter and Histological Features of the Terminal Filum}

Yundt and colleagues ${ }^{52}$ found that the diameter of the normal terminal filum is 1.1 or $1.2 \mathrm{~mm}$. In contrast, the minimum diameter claimed for the diagnosis of tethered spinal cord has varied from 1 to $2 \mathrm{~mm} .{ }^{4,9}$ Selden and colleagues ${ }^{29}$ hold an intermediate position by defining the term "minimally tethered cord syndrome" as greater than $1.5 \mathrm{~mm}$. This variation led us to question whether the rule of a thickened filum larger than $2 \mathrm{~mm}$ as a standard for the diagnosis of tethered spinal cord was absolutely necessary. ${ }^{7}$ It became necessary to study the viscoelasticity of the spinal cord and the filum for further analysis of the dynamic mechanisms of TCS. In addition, reports on histological studies of terminal filum removed from patients with tethered spinal cord came to our attention. ${ }^{27,29}$ Our histological studies are described in a later section.

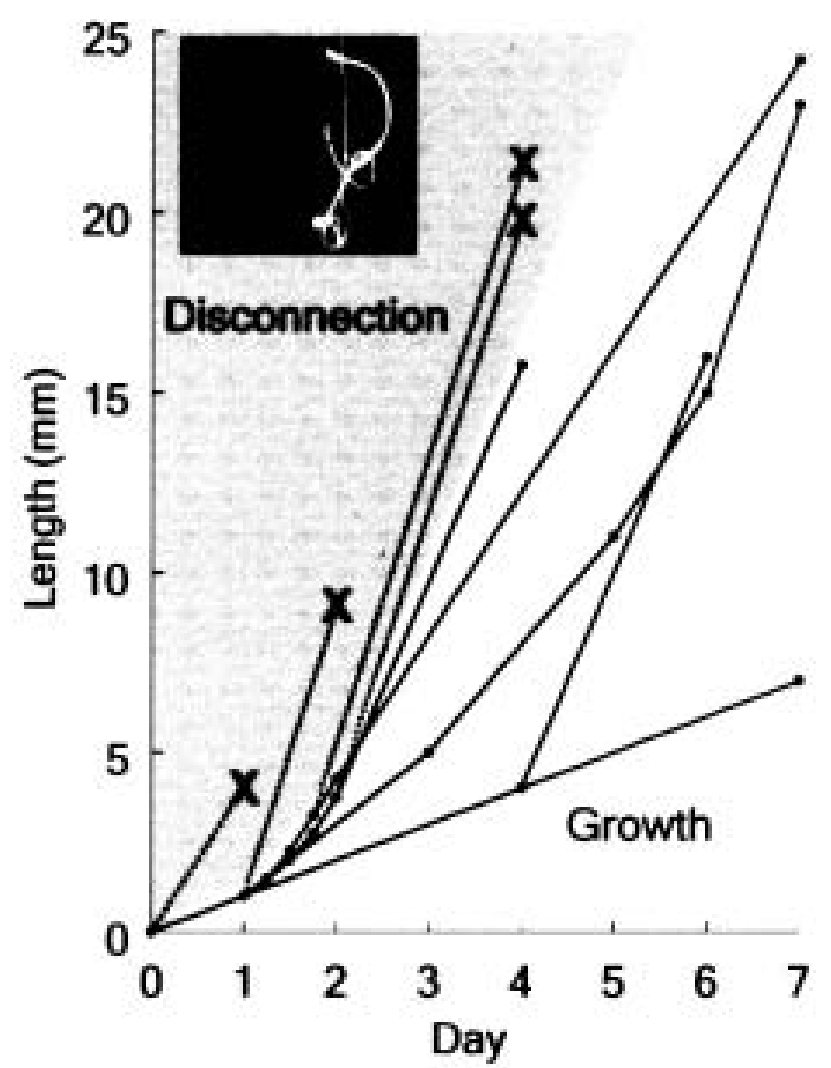

FIG. 1. Graph showing extreme stretch-induced axonal growth. Note the border between the zone of axonal growth and that of disconnection. Reprinted with permission. Copyright 2004 by the Society for Neurosciences.

\section{Posteriorly Displaced Terminal Filum}

The spinal cords of healthy individuals in the supine position are located anteriorly in the thoracic spine, posteriorly in the cervical spine, and more posteriorly in the lumbar spine. Apparently, the spinal cord is shifted toward the concave side of the spinal curvature. Accordingly, the subarachnoid space posterior to the spinal cord and the cauda equina is relatively smaller at the lumbosacral level than at the cervical and thoracic levels.

Normally, the posterior roots cover the entire medullary conus and terminal filum (Fig. 2). In patients with TCS, however, the filum is exposed posterior to the cauda equina (Fig. 3A). This displacement is noted regardless of the presence or absence of cord elongation and filum thickening. We postulate that the taut inelastic terminal filum pushed the normally relaxed posterior roots away laterally during the rapid spinal growth. ${ }^{42}$ The 1 -mm-thick filum, which appears with a fat signal on MR imaging, is posteriorly displaced and touching the posterior arachnoid membrane, and these results correspond with the surgical findings (Fig. 3B).

In patients with TCS, the terminal filum is attached to the posterior arachnoid membrane, usually at the most lordotic position of the spine (that is, the L-4 or -5 lamina). Intraoperative endoscopy of the subarachnoid space confirms displacement of the filum posterior to the cauda 


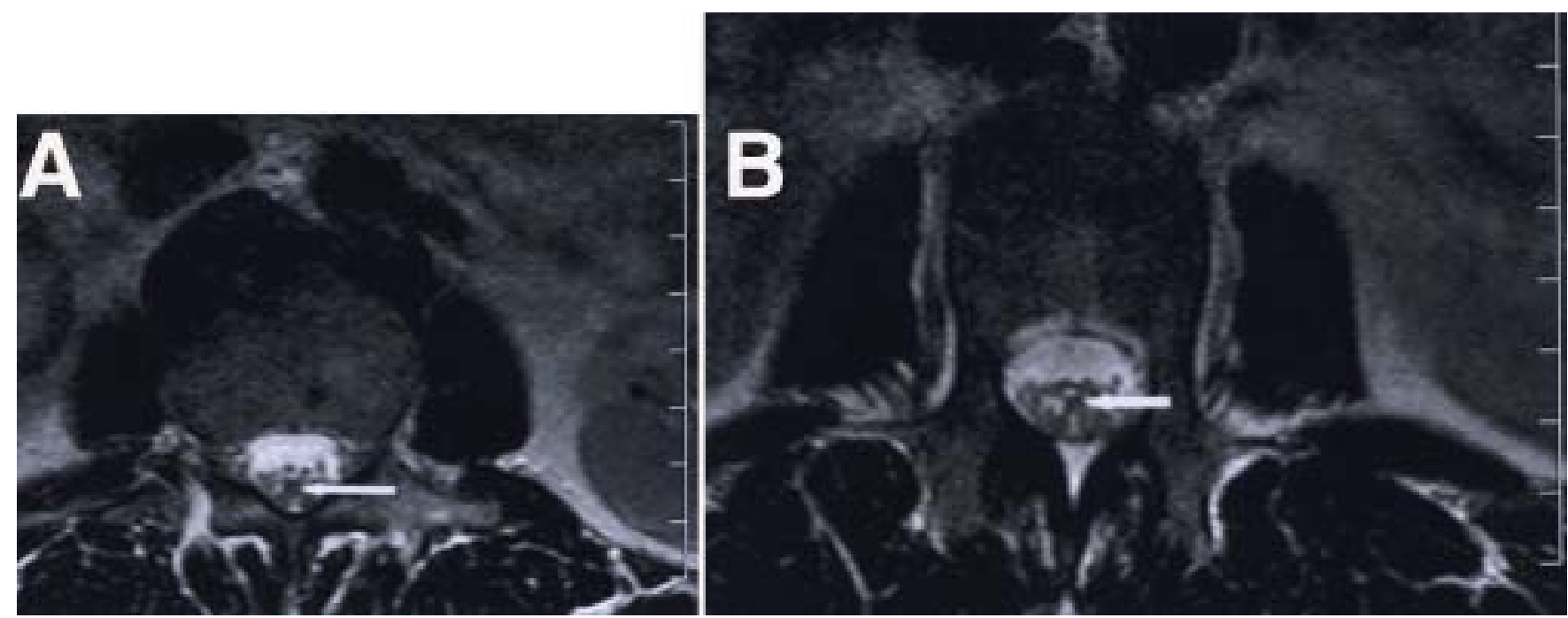

FIG. 2. A: Lumbosacral MR image obtained in a normal individual, showing the lowest medullary cone (arrow) surrounded by cauda equina fibers. B: Lumbosacral MR image demonstrating the terminal filum (arrow) surrounded by cauda equina fibers.

equina and attachment of the filum to the posterior arachnoid membrane (unpublished data). The endoscopy is done before the dura and arachnoid are widely opened to prevent air entry into the subarachnoid space and sinking of the arachnoid and cauda equina anteriorly in the cerebrospinal fluid (Fig. 4).

\section{Stretch Test for Terminal Filum Viscoelasticity}

Normally, natural tension exists in the thoracic cord, dentate ligaments, and dura, as reported by Tunturi ${ }^{34,35}$ and Tubbs et al. ${ }^{33}$ The vertical tension is much less in the lumbosacral cord and dura, ${ }^{35}$ however, reflecting high viscoelasticity of the filum and lack of dentate ligaments.

In our laboratory, we conducted elongation studies in which traction was applied to the cat filum. The filum stretched much greater than any cord segments (Fig. 5A). When traction was applied directly to the spinal cord, cord stretching increased greatly. This condition simulated tethered spinal cord without protection of the elastic filum (Fig. 5B). In contrast, traction-induced elongation extended to higher cord segments at the level where the dentate ligaments were sectioned. ${ }^{32}$

In 100 patients with typical TCS, stretch tests were conducted as follows. The dura and arachnoid membranes were incised in the midline, the posteriorly displaced filum was grasped with two pairs of Cushing forceps at a 1$\mathrm{cm}$ distance, and this filum segment was pulled in opposite directions. The elongation rate of the filum segment was calculated. For comparison purposes, the same stretch test was conducted in five patients with other disorders but no TCS symptoms.

In all of the patients with TCS, stretch tests showed that the terminal filum elongated by $10 \%$ or less and returned to its original length on release of stretching (Fig. 6). In patients without TCS, the filum in each elongated more than $50 \%$, a finding similar to that in animal models. For histological analysis, a 1-cm segment of the filum was resected. It was noted that the cephalic and caudal ends of the resected part of the filum formed a $0.5-$ to $2.5-\mathrm{cm}$ gap.
This finding is consistent with the conclusion that excessive cord tension existed before sectioning of the filum.

\section{Histological Studies of the Terminal Filum in Patients With TCS}

The spinal cord consists of intermingled neurons, glial tissue and vasculature, and the surrounding pia mater tightly connected to the cord substance. Elastin in the pia, subpial tissue, and blood vessels is probably the main source of spinal cord elasticity. Collagen in the dentate ligaments, pia, and blood vessels resists the traction effect and prevents neuronal disruption. From our experimental traction studies on the cat spinal cord and filum, evidently the elasticity of the latter is far greater than the former. $^{32,51}$

Fifty-eight patients with TCS, with or without cord elongation and filum thickening, were included in this study. Fila were resected ( $1 \mathrm{~cm}$ long) for cord untethering, and the specimens were studied using light microscopy. In these patients, normal glia was replaced by fibrous tissue (Fig. 7 left) or by fibroadipose tissue. Elastin staining showed only a small amount of elastin (Fig. 7 right). These pathological features are compatible with minimal viscoelasticity of the filum (10\% elongation by stretch test) in patients with TCS.

Data in this study support the conclusion that an elastic structure continuous with the caudal spinal cord is an essential mechanical factor causing TCS. A minimal amount of elastin in the fibrotic filum is also capable of contracting caudad (approximately 10\%) after partial resection of the filum. Based on clinical and scientific evidence, we conclude that the paucity of filum viscoelasticity is the main predisposing factor for the development of TCS.

\section{Tethered Cord Syndrome in Adults}

In 1982 Pang first described TCS in adults in detail. ${ }^{20}$ Hüttmann and associates, ${ }^{11}$ van Leeuwen et al., ${ }^{37}$ and Lee et al. ${ }^{16}$ reported TCS in adults including those with spinal 

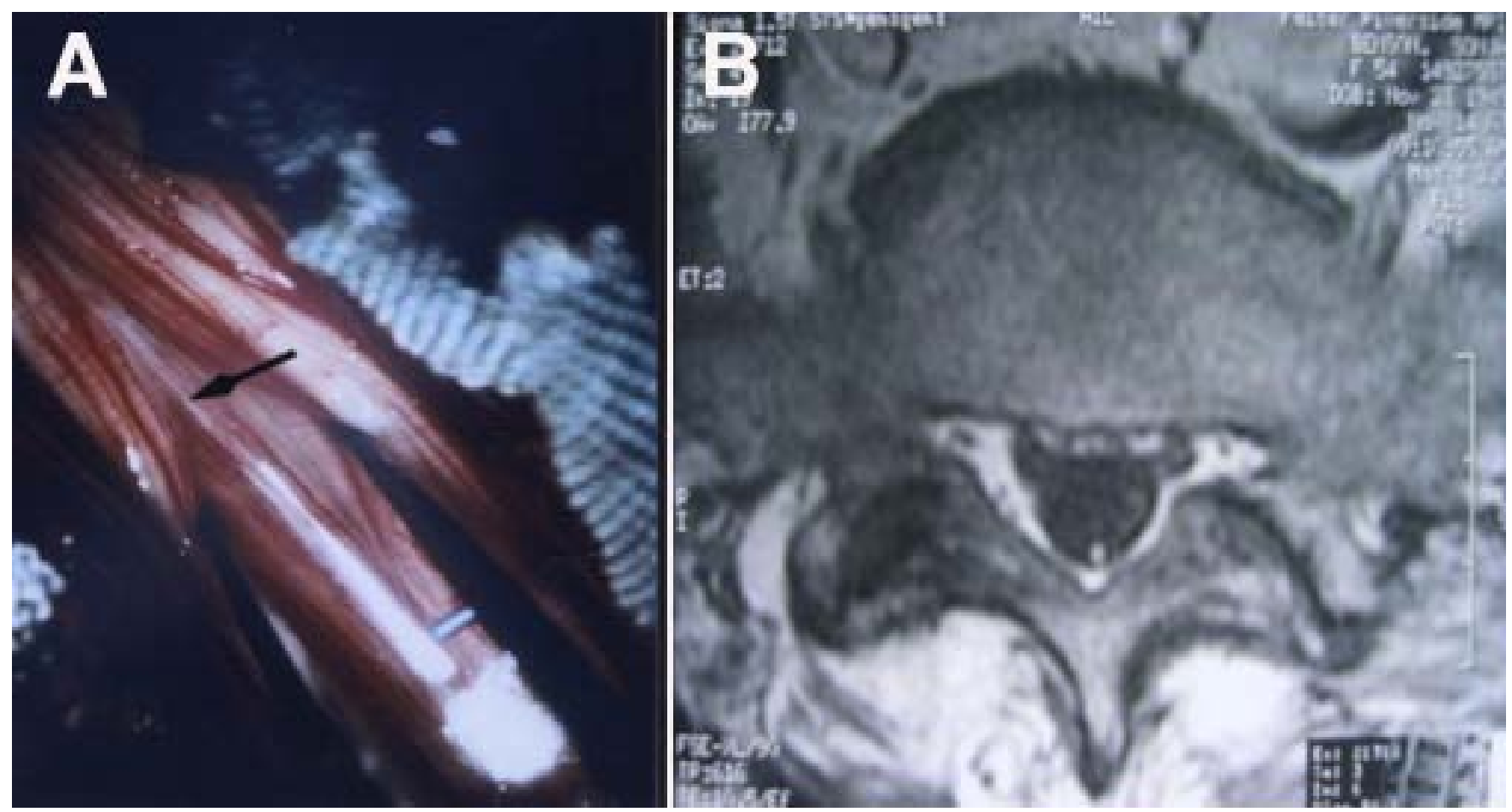

Fig. 3. A: Photograph depicting an abnormal 1-mm-thick terminal filum in an adult with TCS. Note its exposure anterior to the anterior roots (cauda equina) once the dura and arachnoid have been incised. Arrow marks caudal end of spinal cord at the exit of the lowest coccygeal nerve (100 $\mu \mathrm{m}$ in diameter). The lower filum is reflecting light. B: Lumbosacral MR image, axial view, revealing posteriorly displaced filum, touching the posterior arachnoid membrane. View corresponds to the relationship of the filum and cauda equina fibers in the operative field (A).

dysraphism and those with an elongated cord and thickened filum. Iskandar and colleagues ${ }^{12}$ and Lapsiwala et al. ${ }^{15}$ selected patients with TCS associated with spina bifida occulta (occult spinal dysraphism), which included lipomyelomeningocele, meningocele manqué, and a com-

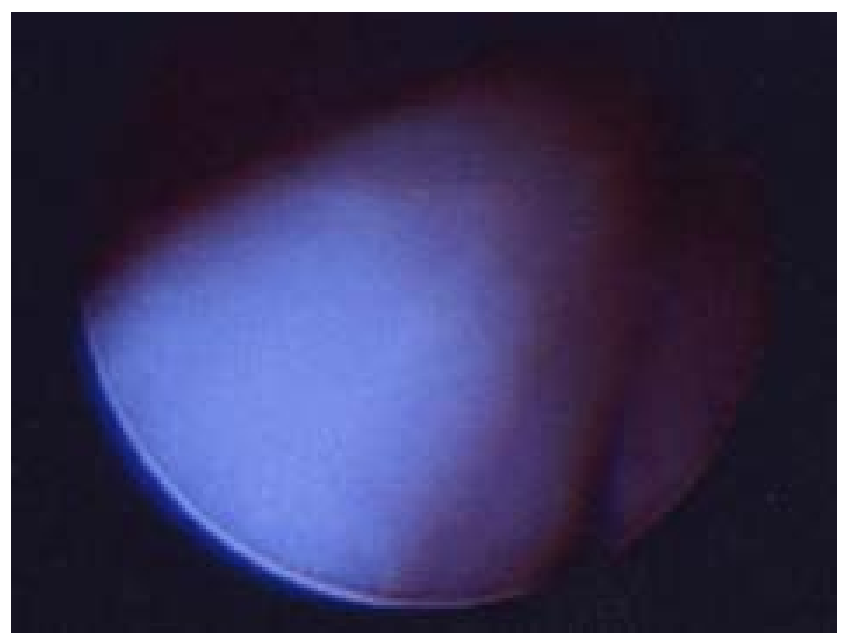

FIG. 4. Image of the subarachnoid space obtained immediately after insertion of an endoscope through a small opening in the dura and arachnoid, revealing a whitish filum. Due to the magnified effect, the filum looks larger near the scope at the bottom of the picture. Note the nerve root on the right side of the filum. Original magnification $\times 15$. bination of an elongated cord and a thick filum. According to the criteria proposed in this report, such cases fit the definitions of Categories 1 and $2 .{ }^{46}$

Yamada and associates ${ }^{42}$ observed TCS in adult and late-teenage patients with an inelastic filum excluding spina bifida aperta or occulta. In this section we focus on Category 1 , or true TCS cases, ${ }^{46}$ and only a small percentage of minimal osseous spina bifida occulta cases were among this group. All patients presented with severe back and leg pain and subtle neurological dysfunction, which subsided after untethering surgery. ${ }^{47}$ The diagnosis of TCS in these patients depends heavily on the signs and symptoms, especially in those without an elongated cord and a thickened filum. ${ }^{44}$

An essential question here is why do patients develop signs and symptoms after having grown to become late teenagers and adults? We believe there are several reasons for this phenomenon. First, let us consider the intrinsic factor: mitochondrial redox activity remains impaired in spinal cords after repeated episodes of forceful spinal flexion and extension that cause cord stretching. The extrinsic factors (outside the spinal cord) include 1) increasing fibrosis of the filum, which leads to progressive loss of its viscoelasticity, thus resulting in progressively increasing tension within the lumbosacral cord above the threshold of its tolerance; 2) a typical growth spurt in late-teenage or early-adult patients, which could cause rapid increases in spinal cord tension (previously marginal to the development of TCS); 3) increases in physical activity, such as running, gymnastics, or contact sports, which could pro- 

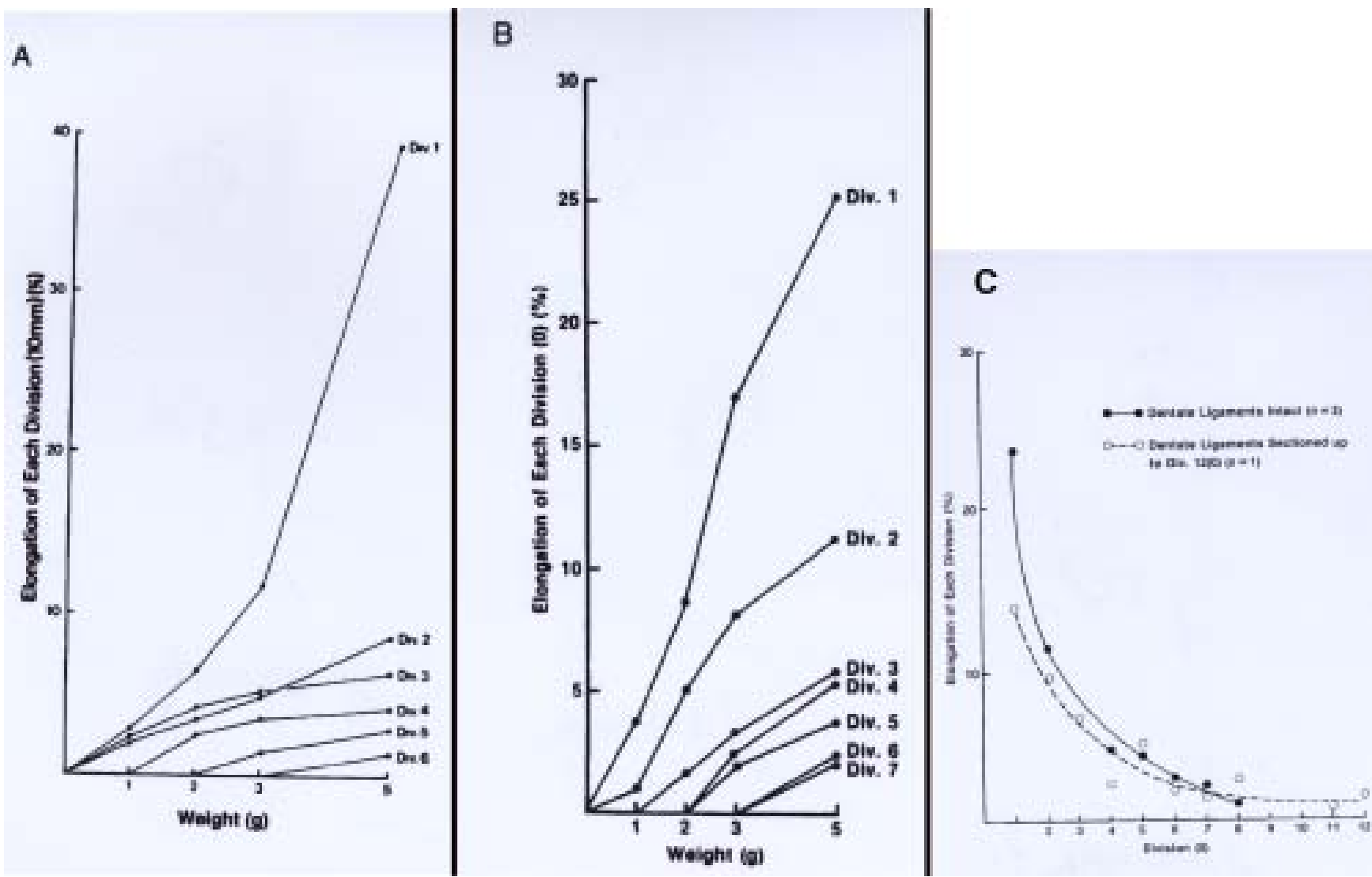

FIG. 5. Graphs showing the results of applying caudal traction to the terminal filum in cats. A: Elongation rate of filum (with a steep rise) and slow rise of the spinal cord segment (Division [Div.] 2 being the lowest and Division 6 being the highest lumbar cord segment). Segments are below the attachment of the lowest dentate ligament (between L-6 and -7). Viscoelasticity of filum is much greater than that of spinal cord. B: Caudal traction applied to the spinal cord tip causes the lowest cord segment to elongate much more than when traction was applied to the filum, but less than the filum in panel A. The same results were obtained for the other cord segments. C: Cord elongation extended to the higher level when the dentate ligaments were sectioned, compared with the extension rate of the spinal cord with dentate ligaments intact.

duce stresses to the spine and spinal cord; 4) osteoarthritic spinal stenosis, which restricts movement of the spinal cord and filum and may accentuate vertical tension within the spinal cord.

\section{Diastematomyelia and Split Cord}

Pang extensively studied the split spinal cord and associated TCS. ${ }^{19}$ According to the author's analysis, TCS often develops in patients with an osseous septum dividing the spinal cord into two lateral halves. There are four possible factors that cause mechanical stretching of the spinal cord. 1) The upper edge of the osseous septum, incorporated with fibrous tissue that includes the underlying dura and arachnoid membrane and pia mater, anchors the bifurcation of the split cord. ${ }^{43}$ 2) The lower osseous edge pulls against the caudal reunion of the split cord as the spine rapidly grows cephalad in the vertical plane. ${ }^{8} 3$ ) The fibrous terminal filum acts as caudal tethering of the united spinal cord. 3) In some cases, the split cord segments do not unite, and each segment continues to a separate filum. One or both of them has been inelastic, causing cord tethering. ${ }^{50}$ The stretching effect on the short cord segment between the inelastic filum (tethering site) and the osseous septum (counteracting site) is accentuated as the spine grows. In addition, congenital dysgenesis of the spinal cord must be considered as a possible cause of neurological deficits. ${ }^{40}$

These various factors produce different neurological conditions. For instance, the osseous septum separating the high lumbar and thoracic cord may cause combined upper and lower motor lesions. The osseous or dural septum in the caudal part of an elongated cord causes lower motor neuron lesions similar to the myelomeningocele or lipomyelomeningocele located in the lower lumbar and sacral cord. The levels of cord lesions vary in relation to the vertebral level of the septum, depending on the degree of cord elongation.

\section{Incontinence and TCS}

Recently, three groups of authors have discussed "occult TCS," with incontinence in patients who showed no cord elongation and filum thickening. ${ }^{3,28,31}$ It is reasonable to assume that TCS can be manifested by incontinence alone, because results of our experimental work 

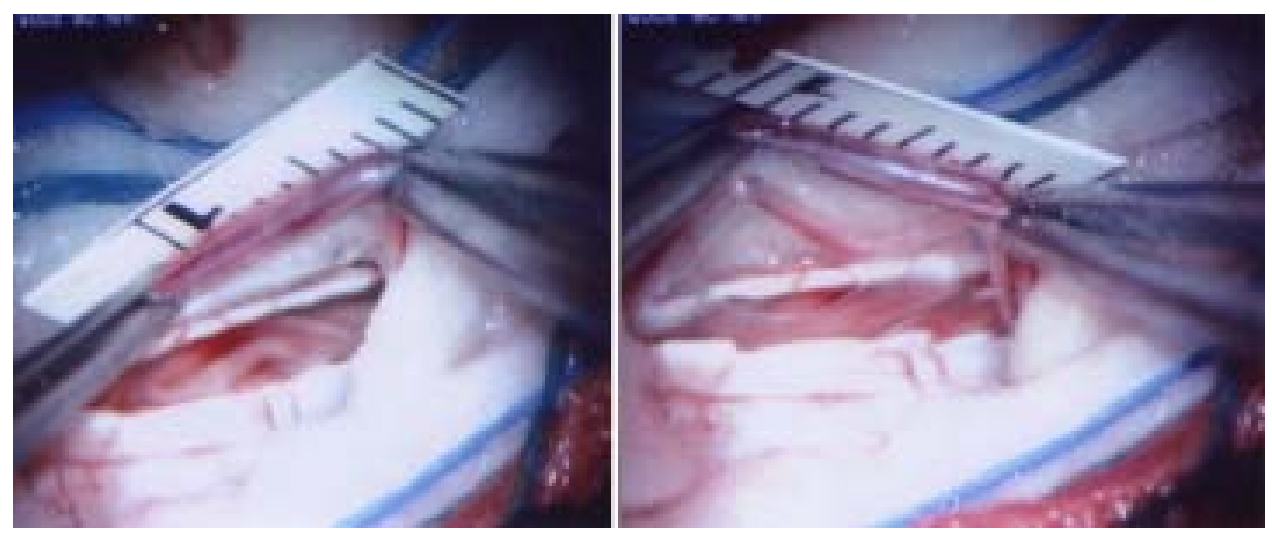

FIG. 6. Left: Photograph demonstrating a 7-mm segment of the filum held in place with two pairs of forceps. Right: Photograph showing the filum pulled in opposite directions with two pairs of forceps. Only slight elongation $(\geq 10 \%)$ occurred concomitant with thinning of the filum.

have indicated that the medullary cone is most vulnerable to traction-induced dysfunction. When the reliability of MR imaging findings was discussed in a questionnaire, ${ }^{31}$ all neurosurgeons agreed that they would consider surgery in the presence of positive findings such as elongated cord, thick filum, and fat signal in the filum in patients who experienced incontinence along with motor and sensory dysfunction. Without such MR imaging signs, neurosurgeons' opinions were divided regarding surgical indications.

As described by Yamada and $\mathrm{Won}^{45}$ we recommend conducting additional diagnostic studies, including anal sphincter contraction tests, intra- or preoperative subarachnoid endoscopy to confirm displacement of the filum posterior to the cauda equina, filum stretch test to determine filum viscoelasticity, histological analysis of the resected filum, and, if available, in vivo reflection spectrophotometry to demonstrate reduced state of cytochrome oxidase in spinal cord mitochondria. Interpolation of the data thus obtained will allow authors of interinstitutional studies to better interpret MR imaging findings.

\section{Other TCS-Related Conditions}

Although the following subjects are important in an analysis of TCS, we comment on them only briefly.

Myelomeningocele. The treatment and prognosis of myelomeningocele as well as its intricate association with TCS have been discussed elsewhere. ${ }^{48}$

Musculoskeletal Abnormalities. Scoliosis and exaggerated lumbosacral lordosis, high arched feet, and hammertoes associated with TCS are due to unbalanced muscle function and must be distinguished from congenital anomalies such as hip dislocations, club foot, and hemivertebrae.

Somatosensory Evoked Potential Studies. The majority of SSEP studies of TCS in humans rely on posterior column conduction. According to data from our experimental traction studies on cat cords, only interneuron potentials are deranged in the gray matter, and posterior column conduction is intact. Signs in patients with typical TCS also correspond with symptoms caused by gray matter lesions. ${ }^{44}$ Changes in SSEPs recorded from the cerebral cortex may be difficult to quantify. Readers may refer to the SSEP studies conducted by Gilmore and Walsh ${ }^{6}$, who demonstrated impaired potentials in the long tracts transmitted through the interneurons.

\section{Conclusions}

The pathophysiology of TCS is associated with impaired oxidative metabolism in the affected spinal cord. This interpretation is supported by studies of mitochondrial redox activity, impaired glucose metabolism, decreases in blood flow, and deterioration of interneuron potentials in experimentally tethered spinal cords. Cords in patients with TCS showed similar mitochondrial and neurological changes. There was no histological evidence of cell damage according to either light or electron microscopic examination following the application of traction to the spinal cord. Metabolic and neurological dysfunction were reversed via untethering surgery in humans with TCS.

Tethered cord syndrome is associated with inelastic structures anchoring the caudal end of the spinal cord. Anomalies located in the dorsal aspect of the lumbosacral spinal cord, such as myelomingoceles, lipomyelomeningoceles, lipomas, and meningocele manqué, may cause a combination of TCS and local effect on the spinal cord. Severely symptomatic cases with these anomalies may involve total paraplegia, and the term "TCS" is not applicable.

An elongated cord and a thick terminal filum may be related to increased tension that occurred in the embryonic stage, and these features support the diagnosis of TCS if the signs and symptoms localize the lesion to the lumbosacral cord.

\section{Acknowledgment}

We thank Myron Rosenthal, Ph.D., University of Miami School of Medicine, for his continuous advice on physiological studies of TCS and for reviewing this article.

\section{References}

1. Barry A, Pattern BM, Stewart BH: Possible factors in the development of the Arnold-Chiari malformation. J Neurosurg 14: 285-301, 1957 


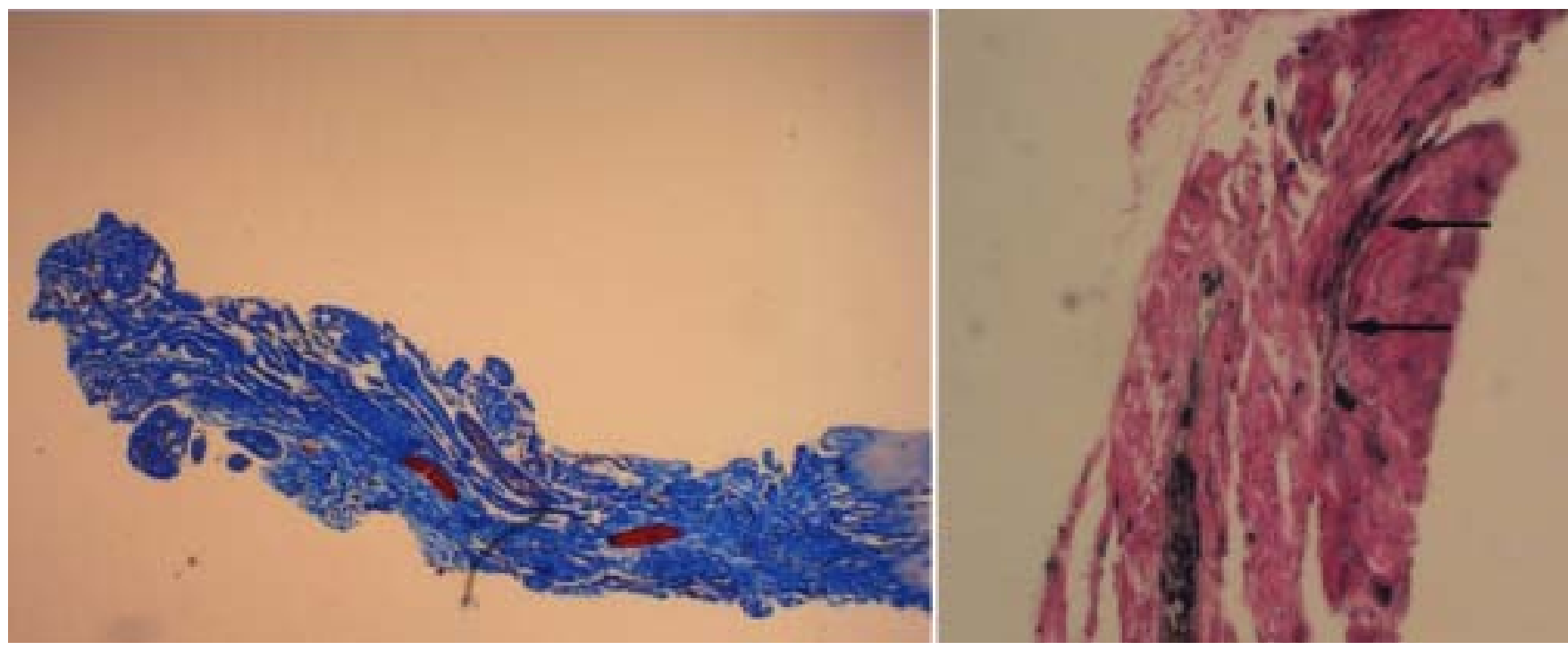

FIG. 7. Left: Photomicrograph of representative histological section of filum removed from the patient with typical TCS, showing replacement of the entire filum with fibrous tissue. Right: Photomicrograph revealing fibrotic terminal filum with sparse, thin, and discontinuous elastic fibers (black areas indicated by arrows) running in between and parallel to the collagen (pink). Blood vessels at the left lower corner have abundant elastin. Mallory trichrome (left) and elastin stain $($ right), original magnification $\times 400$.

2. Barson AJ: The vertebral level of termination of the spinal cord during normal and abnormal development. J Anat 106: 489-497, 1970

3. Drake JM: Occult tethered cord syndrome: not an indication for surgery. J Neurosurg 104 (5 Suppl):305-308, 2006

4. Fritz CR, Harwood-Nash DC: The tethered conus. AJR Radium Ther Nucl Med 125:515-523, 1975

5. Gardner WJ, Smith JL, Padget DH: The relationsip of ArnoldChiari and Dandy-Walker malformations. J Neurosurg 36: 481-489, 1972

6. Gilmore RL, Walsh J: The clinical neurophysiology of tethered cord syndrome and other dysraphic syndromes, in Yamada $S$ (ed): Tethered Cord Syndrome. Park Ridge, Ill: American Association of Neurological Surgeons, 1996, pp 167-182

7. Greenberg MS (ed): Handbook of Neurosurgery. NewYork: Thieme, 2001

8. Guthkelch AN, Hoffmann GT: Tethered spinal cord in association with diastematomyelia. Surg Neurol 15:352-354, 1981

9. Hochhauser L, Chaung S, Harwood-Nash DS, Armstrong D, Savoie J: The tethered cord syndrome revisited. AJNR Am J Neuroradiol 7:543, 1986 (Abstract)

10. Hoffman HJ, Hendrick EB, Humphreys RP: The tethered spinal cord: its protean manifestations, diagnosis and surgical correction. Childs Brain 2:145-155, 1976

11. Hüttmann S, Kraus J, Collman H, Sörensen N, Roose K: Surgical management of tethered spinal cord in adults: report of 54 cases. J Neurosurg 95 (2 Suppl):173-178, 2001

12. Iskandar BJ, Fulmer BB, Hadley MN, Oakes WJ: Congenital tethered spinal cord syndrome in adults. J Neurosurg 88: 958-961, 1998

13. Jöbsis FF, Keizer JH, LaManna JC, Rosenthal M: Reflectance spectrophotometry of cytochrome aa3 in vivo. J Appl Physiol 43:858-872, 1977

14. Kang JK, Kirn MC, King DS, Song JU: Effects of tethering on regional spinal cord blood flow and sensory-evoked potentials in growing cats. Childs Nerv Syst 3:35-39, 1987

15. Lapsiwala SB, Samir B, Iskandar BJ: The tethered cord syndrome in adults with spina bifida occulta. Neurol Res 26: 730-740, 2004

16. Lee GYF, Gong GWK, Paradiso G, Fehlings MG: Tethered cord syndrome: clinical considerations and surgical management. Neurosurg Q 16:55-66, 2006

17. Lichtenstein BM: "Spinal dysraphism." Spina bifida and myelodysplasia. Arch Neurol Psychiatry 44:792-809, 1940

18. McLone DC, Naidich TP: The tethered spinal cord, in McLaurin RL, Schut L, Venes JL, Epstein F (eds): Pediatric Neurosurgery, ed 2. Philadelphia: WB Saunders, 1989, pp 76-96

19. Pang D: Split cord malformation, in Pang D (ed): Disorders of the Pediatric Spine. New York: Raven Press, 1995, pp 203-252

20. Pang D, Wilberger JE: Tethered cord syndrome in adults. J Neurosurg 57:32-47, 1982

21. Pfister BJ, Iwata A, Meaney DF, Smith DH: Extreme stretch growth of integrated axons. J Neurosci 24:7978-7983, 2004

22. Purtzer T, Yamada S, Tani S: Metabolic and histologic studies of chronic model of tethered cord. Surg Forum 36:512-514, 1985

23. Reigel DH: Spinal bifida, in McLaurin RL, Schut L, Venes JL, Epstein F (eds): Pediatric Neurosurgery, ed 2. Philadelphia: WB Saunders, 1989, pp 35-52

24. Rosenthal M, LaManna J, Yamada S, Younts W, Somjen G: Oxidative metabolism, Extracellular potassium and sustained potential shift in cat spinal cord in situ. Brain Res 162: 113-127, 1979

25. Schneider SJ, Rosenthal AD, Greenberg BM, Danto J: A preliminary report on the use of laser-Doppler flowmetry during tethered spinal cord release. Neurosurgery 32:214-218, 1993

26. Scott RM: Delayed deterioration in patients with spinal tethering syndromes, in Holtzman RNN, Stein BM (eds): The Tethered Spinal Cord. New York: Thieme-Stratton, 1985, pp $116-120$

27. Selcuki M, Vatansever S, Inan S, Erdemli E, Bagdatoglu C, Polat A: Is the filum terminale with a normal appearance really normal? Childs Nerv Syst 19:3-10, 2003

28. Selden NR: Occult tethered cord syndrome: the case for surgery. J Neurosurg 104 (5 Suppl Pediatrics):302-304, 2006

29. Selden NR, Nixon RR, Skoog SR, Lashley DB: Minimal tethered cord syndrome associated with thickening of the terminal filum. J Neurosurg (3 Suppl Pediatrics) 105:214-218, 2006

30. Sokoloff L, Reivich M, Kennedy C, Des Rosiers MH, Patlak 
CS, Pettigrew KD, et al: The [14C]deoxyglucose method for the measurement of local cerebral glucose utilization: theory, procedure, and normal values in the conscious and anesthetized albino rat. J Neurochem 28:897-916, 1977

31. Steinbok P, Garton HJ, Gupta N: Occult tethered cord syndrome: a survery of practice patterns. J Neurosurg 104 (5 Suppl):309-313, 2006

32. Tani S, Yamada S, Knighton R: Extensibility of the lumbar and sacral spinal cord. Pathophysiology of tethered spinal cord in cats. J Neurosurg 66:116-123, 1987

33. Tubbs RS, Salter G, Grabb PA, Oakes WJ: The denticulate ligament: anatomy and functional significance. J Neurosurg 94 (2 Suppl):271-275, 2001

34. Tunturi AR: Elasticity of the spinal cord dura in the dog. J Neurosurg 47:391-396, 1977

35. Tunturi AR: Elasticity of the spinal cord, pia, and denticulate ligament in the dog. J Neurosurg 48:975-979, 1978

36. Turnbull IM, Breig A, Hassler O: Blood supply of cervical spinal cord in man. A microangiographic cadaver study. J Neurosurg 24:951-965, 1966

37. van Leeuwen R, Notermans NC, Vandertop WP: Surgery in adults with tethered cord syndrome: outcome study with independent clinical review. J Neurosurg 94 (2 Suppl):205-209, 2001

38. Warder DE, Oakes WJ: Tethered cord syndrome and the conus in a normal position. Neurosurgery 33:374-378, 1993

39. Yamada S, Iacono RP, Andrade T, Mandybur G, Yamada BS: Pathophysiology of tethered cord syndrome. Neurosurg Clin N Am 6:311-323, 1995

40. Yamada S, Iacono RP, Yamada BS: Pathophysiology of the tethered spinal cord, in Yamada S (ed): Tethered Cord Syndrome. Park Ridge, Ill: American Association of Neurological Surgeons, 1996, pp 29-48

41. Yamada S, Kneium DB, Won DJ, Figuereo SJ, Almagud F: Are lipomyelomeningoceles always associated with tethered cord syndrome? J Neurosurg 96:414, 2002 (Abstract)

42. Yamada S, Lonser RR: Adult tethered cord syndrome. J Spinal Disord 13:319-323, 2000
43. Yamada S, Mandybur GT, Thompson JR: Dorsal midline proboscis associated with diastematomyelia and tethered cord syndrome. Case report. J Neurosurg 85:709-712, 1996

44. Yamada S, Siddiqi J, Won DJ, Kido D, Hadden A, Spitalieri J, et al: Symptomatic protocols for adult tethered cord syndrome. Neurol Res 26:741-744, 2004

45. Yamada S, Won DJ: Occult tetherd cord syndrome. J Neurosurg 106:411-414, 2007 (Letter)

46. Yamada S, Won DJ: What is the true tethered cord syndrome? Childs Nerv Syst 23:371-375, 2007

47. Yamada S, Won DJ, Kido DK: Adult tethered cord syndrome: new classification correlated with symptomatology, imaging and pathophysiology. Neurosurg Q 11:260-275, 2001

48. Yamada S, Won DJ, Yamada SM: Pathophysiology of tethered cord syndrome and clinical correlation. Neurosurg Focus 16(2):E6, 2004

49. Yamada S, Won DJ, Yamada SM, Hadden A, Siddiqi J: Adult tethered cord syndrome: relative to spinal cord length and filum thickness. Neurol Res 26:732-734, 2004

50. Yamada S, Yamada SM, Mandybur GT, Yamada BS: Conservative versus surgical treatment and tethered cord syndrome prognosis, in Yamada S (ed): Tethered Cord Syndrome. Park Ridge, Ill: American Association of Neurological Surgeons, 1996, pp 183-202

51. Yamada S, Zinke DE, Sanders D: Pathophysiology of "tethered cord syndrome." J Neurosurg 54:494-503, 1981

52. Yundt KD, Park TS, Kaufman BA: Normal diameter of filum terminale in children: in vivo measurement. Pediatr Neurosurg 1:257-259, 1997

Manuscript submitted June 13, 2007.

Accepted July 13, 2007.

Address correspondence to: Shokei Yamada, M.D., Ph.D., 11234

Anderson Street, Loma Linda, California 92354. email: yamada1000.gmail.com. 